\title{
Creating Stealth Game Interventions for Attitude and Behavior Change: An "Embedded Design" Model
}

\author{
Geoff Kaufman, Mary Flanagan, Max Seidman \\ Tiltfactor Laboratory, Dartmouth College \\ 245 Black Family Visual Arts Center \\ Hanover NH 03755 USA \\ 603-646-1007 \\ geoff.kaufman@dartmouth.edu; mary.flanagan@dartmouth.edu; \\ max.seidman@dartmouth.edu
}

\begin{abstract}
Persuasive games tackling serious issues in a literal, explicit fashion are far less likely to succeed in changing attitudes or behaviors than are games that take the more "stealthy" approach of embedding persuasive messages within a game's content or context. The "Embedded Design" model, which we introduce here, offers novel, evidence-based strategies for including persuasive content in a game in a fashion that circumvents players' psychological defenses, triggers a more receptive mindset for internalizing a game's intended message, and does so without sacrificing players' enjoyment or the game's replayability. Such techniques promise to revolutionize the ways that game developers tackle serious issues in games. Three original "embedding" strategies are presented: (1) Intermixing: balancing "on-message" and "off-message" content to render the former less overt or threatening; (2) Obfuscating: using framing devices or genres that divert expectations or focus away from the game's persuasive intent; and (3) Distancing: employing fiction and metaphor to increase the psychological gap between players' identities and beliefs and the game's characters and persuasive content.
\end{abstract}

\section{Keywords}

Persuasive games, attitude change, behavior change, embedding, game design

\section{INTRODUCTION}

The past several decades have seen the emergence of a plethora of persuasive games that aim to increase players' awareness of critical and timely social issues - and to change players' attitudes and behaviors - through gameplay (Bogost 2007). Running the gamut from games targeting cognitive biases that reduce the accuracy of judgment and decision making (e.g., the SIRIUS initiative of the Intelligence Advanced Research Projects Activity program: Dunbar et al. 2013) to ones intended to encourage behaviors that benefit society (such as recycling in the case of the mobile game Gaea: Centieiro, Romão, and Dias 2011) or the self (e.g., the reduction of substance abuse and HIV risk, which is the focus of the "Play2Prevent" program: Fiellin et al. 2014), this subset of "serious games" is united by their intention to transform mindsets and actions through the messages they model.

\section{Proceedings of DiGRA 2015: Diversity of play: Games - Cultures - Identities}

(C) 2015 Authors \& Digital Games Research Association DiGRA. Personal and educational classroom use of this paper is allowed, commercial use requires specific permission from the author. 
Games themselves are powerful sites for enculturation (Flanagan 2009). A vast majority of serious games, however, share a common design philosophy: by and large, they present characters, scenarios, situations, and solutions in a direct, matter-of-fact fashion under the ostensibly logical (and well-intentioned) assumption that doing so will automatically encourage and enable players to internalize, and transfer, the game's modeled beliefs and behaviors to real-life contexts.

In light of what is known in contemporary psychology, this approach, we argue, is illadvised at best and potentially harmful at worst, particularly when dealing with persuasive content that is uncomfortable, psychologically threatening, or counterattitudinal. A vast body of social psychological theories and research on persuasion and attitude change has long demonstrated that it is a basic human tendency to resist persuasive communications that are perceived as too forceful or forthright in their intentions. For one, being aware that some external agent is aiming to change one's attitudes or behaviors triggers psychological reactance: an aversive state of arousal that arises whenever one perceives that his/her freedom to do or think freely is being threatened (Brehm 1966). The aversive state of reactance raises individuals' psychological defenses, rendering them less receptive (and, indeed, more resistant) to a persuasive message. What's even more surprising is that psychological reactance will occur even if a person's own beliefs align with the content of the message (e.g., Worchel and Brehm 1970).

A second psychological barrier that comes into play in situations of persuasion and play, especially when dealing with attitudes and behaviors of a particularly sensitive nature (such as the hot-button issues of stereotypes and prejudice), is the bias blind spot: the acknowledgment that biases exist but the denial or minimization of one's own susceptibility to those biases (e.g., Pronin, Lin, and Ross 2002).

The potentially aversive and defensive reactions triggered by explicit persuasive attempts limit not only the potential efficacy of game-based interventions, but also players' enjoyment of them, for the perception of a persuasive agenda is inherently antithetical to players' immersion within a game world (and, indeed, antithetical to the notion of play itself: see de la Hera Conde-Pumpido 2013; Huizinga 1938). In other words, most persuasive games may fail to engage players, let alone immerse them in a transformative experience, due to normal psychological human reactions to overtly "message-driven" interventions.

For this reason, we propose that persuasive games would greatly benefit from using a more subtle, stealthy approach to presenting their focal messages or themes. This line of thinking is directly informed by our team's research at the Tiltfactor Lab, which has, for over a decade, sought to tease out effective means for fostering social engagement and enacting persuasive, prosocial interventions in game design. Under the direction of Dr. Mary Flanagan, the laboratory team has been building a body of evidence showing how games can significantly shape perceptions and change ways of thinking. The lab started by creating more "statement" style games that explored issues as matters for debate or conversation; these games were assumed to impact or inform the players in the same fashion as documentary films and other similar art forms. Through time, the team has shifted to focus more on an evidence-based approach to design, using formal experimental methods and a psychologically grounded approach to demonstrate our games' impact on players. As this evolution has occurred, the team has developed novel strategies, including those discussed in this paper, to address controversial topics, such as 
public health attitudes and social and cognitive biases, in a more nuanced, less direct fashion. In this paper, we propose our novel model of "Embedded Design" that offers key strategies for tackling social issues and including persuasive content in a game in ways that circumvent players' psychological defenses, trigger a more receptive mindset for internalizing the game's intended message, and do so without sacrificing players' enjoyment or the game's replayability.

\section{THE "EMBEDDED DESIGN" MODEL}

The key premise of the Embedded Design model is that the persuasive impact of gamebased interventions is greatly enhanced when interweaving a focal message within the game's content, mechanics, or context of play, rather than making the message or the game's persuasive aims the focal point. Through our team's longstanding work in the design and study of games intended to shift attitudes and behaviors, we have uncovered a number of distinct embedding strategies that have proven effective at increasing our games' persuasive impact (see Figure 1). This work is informed in part by the Values in Design and the Values at Play methodology, which offers over many avenues at which values might emerge in any given game experience (see Flanagan and Nissenbaum 2014).

In this paper, we will focus on three distinct strategies, each representing a unique manifestation of embedding, that have emerged thus far in our work: (1) Intermixing: balancing "on-message" and "off-message" content to render the former less overt or threatening and more palatable and approachable; (2) Obfuscating: using framing devices or genres that divert expectations or focus away from the game's persuasive intent; and (3) Distancing: employing techniques, such as the use of fictional or metaphorical representations of key issues or themes in order to increase the psychological gap between players' identities and beliefs and the game's characters and persuasive content. In the sections that follow, we expound upon these three strategies and provide concrete examples of our team's game designs to illustrate their implementation and cite the results of empirical investigations that support their efficacy.

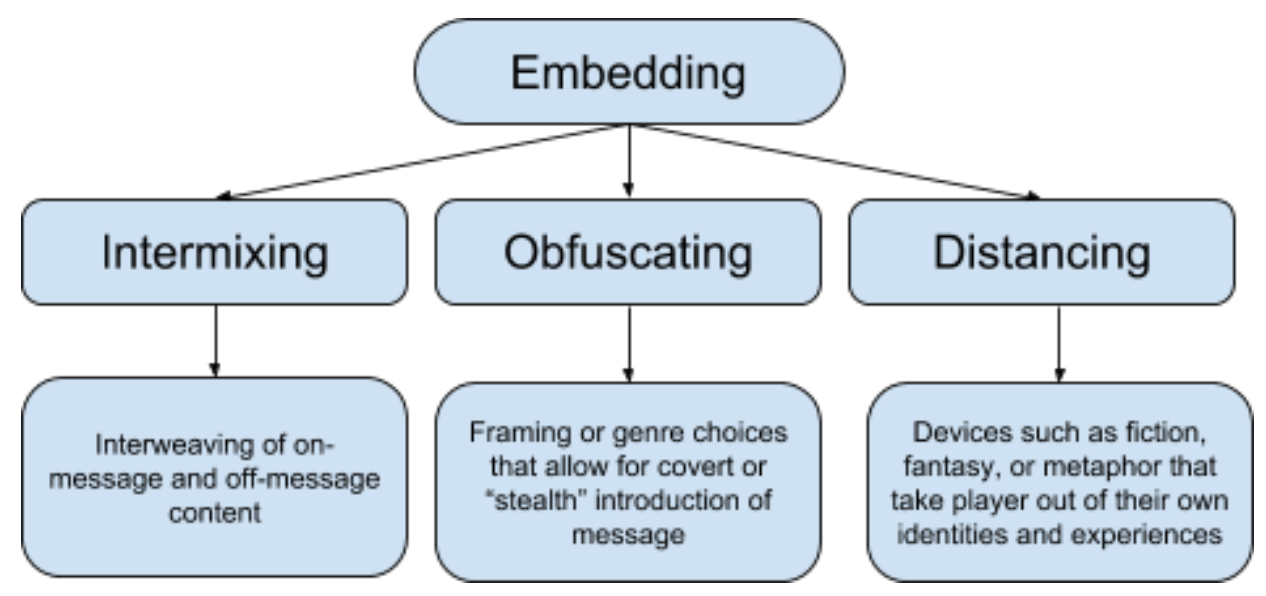

Figure 1: The "Embedded Design" Model.

\section{Embedding through "Intermixing"}

One means of embedding persuasive content within a game's design is a strategy we have come to refer to as "intermixing": balancing or interweaving on-topic content with playful but persuasively off-topic (or off-focus) content that either distracts from the 
intended message of the game or helps ease player into the game's message or aims. This strategy, when implemented effectively, reduces the likelihood of players experiencing the game as a top-down attitude or behavior change intervention and offsets the serious (or potentially uncomfortable) tone of the "on-message" components of the game with content with comparatively more levity or humor.

Our team has implemented and tested the intermixing strategy in several game designs. To cite one illustrative example, Awkward Moment (2012) is a party game for pre- and early-adolescent players that aims to reduce social biases, including gender stereotypes in science, technology, engineering, and math (STEM) domains (see Figure 2). In Awkward Moment, players begin with a hand of five "Reaction Cards"; these cards describe potential responses to the game's "awkward moments," including actions (e.g., "Scream your head off," "Write a blog post about it," "Talk it out"), exclamations (e.g., "Rats!" "OMG," "No way!"), and frames of mind (e.g., "Get serious," "Relax," "Channel your inner warrior"). During each round, one player serves as the "Decider" and draws a "Moment Card" that poses a hypothetical situation (e.g., "Somebody hacks your Facebook account and changes your status to "Girls are stupid."'), to which the other players respond by submitting a Reaction Card face-down. The Decider then reads each of the submitted cards and selects a winner for the round. The game aims to stimulate thought and discussion about responses to social and academic dilemmas, particularly situations that involve bias against girls and women in STEM. A subset of the cards in the Moment deck present situations in which a female is a target of stereotypes. In some situations, players imagine being a target themselves. The game's deck of Moment cards contain examples depicting both on-topic scenarios related to gender bias in STEM (see Figure 2 for an example), as well as off-topic scenarios presenting awkward situations that do not directly pertain to social biases (e.g., "You sit on ketchup" or "There's a secret 'Ugly Poll' at school, and you find out you were Number 3 on the list").
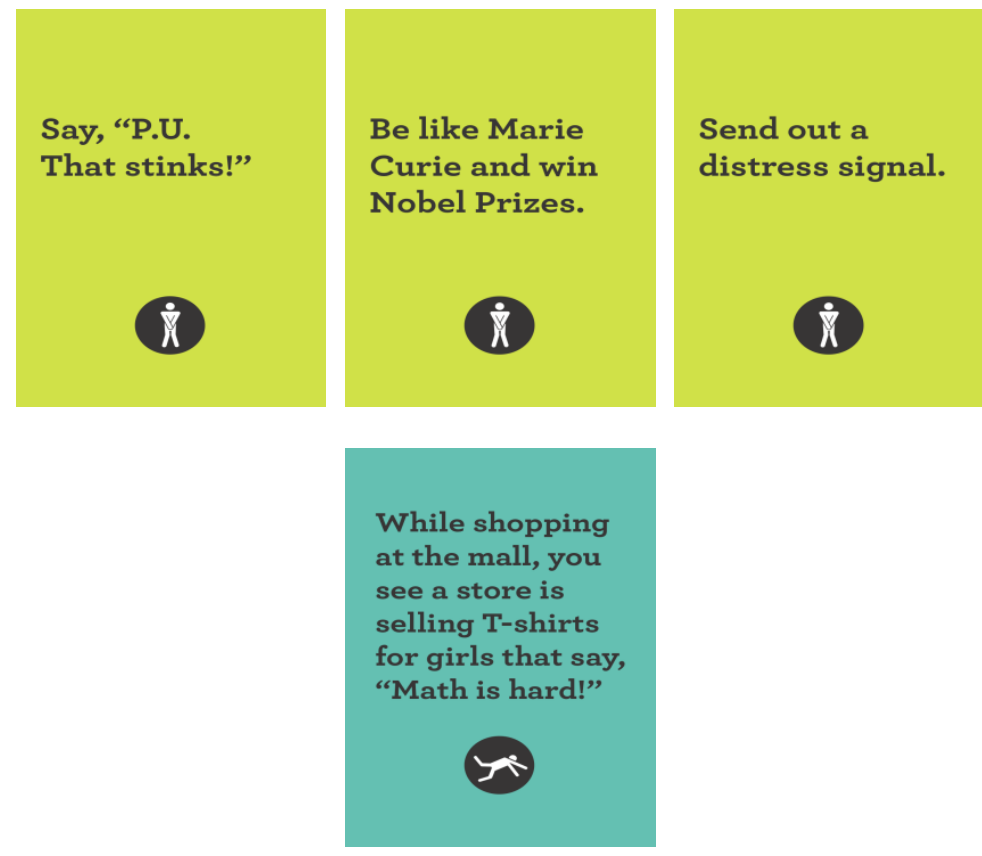

Figure 2: Sample Reaction Cards (green) and sample Moment Card (blue) from Awkward Moment. 
A key question that guided the iterative design of Awkward Moment was the ideal ratio of on-topic to off-topic Moments in the game. In line with the intermixing strategy, our empirical research showed that presenting a lower ratio of bias-themed to non-biasthemed Moments proved much more effective at shifting players' attitudes and perceptions. One of our controlled experiments (Kaufman and Flanagan 2015A) revealed that youth participants randomly assigned to play an "intermixed" version of the game (with approximately $45 \%$ of the Moment cards depicting gender bias in STEM) exhibited statistically significant higher post-game levels of perspective-taking, compared to participants assigned to play an "overloaded" version of the game (with $75 \%$ of the Moment Cards pertaining to bias). In another experiment, an "intermixed" version of the game produced a threefold increase in players' likelihood of associating women and science after one gameplay session. In both of these studies, we observed little evidence of players noticing, let alone reacting against, the game's persuasive content because it was not the ostensible subject or focus of the game.

An additional study involving a new version of the game for adults (depicting workplace scenarios) and utilizing the same methodology as the aforementioned experiment revealed the same pattern of results with adult participants. Those participants assigned to play an "overloaded" version of the game exhibited significantly greater negative affect (including the distinct response of feeling "fed up" by the end of the game) and a lower level of concern about the issue of social biases, compared to participants assigned to either an "intermixed" game condition or a no-game control condition (Kaufman and Flanagan 2015B). In sum, these findings confirm that over-representing serious, persuasive content within the game triggered players' reactance - and that this defensiveness prevented them from shifting their mindsets and perceptions after play.

In recent work, we have explored how the intermixing strategy might also be effectively implemented in a game's presentation of diverse characters as a means of reducing gender bias in STEM. In the time travel-themed strategy game The Luminists, players compete to "restore" the most scientific and technological discoveries that have been undone by the unraveling of time by "recruiting" real-life STEM role models whose skills and expertise assist them in their quest. In line with prior work demonstrating the beneficial impact of exposure to counterstereotypical role models for lowering social biases and increasing STEM aspirations and pursuits (e.g., Dasgupta and Asgari 2004), the primary underlying goal of the game was to present a host of positive female STEM role models to young female players. At the same time, we predicted that "intermixing" female and male STEM role model "luminists" (rather than presenting a higher ratio of female to male luminists) would enhance the efficacy of the game - both by making the intended goals of the game less overt and by reinforcing equity rather than imbalanced participation in STEM between the genders. An initial experimental study involving a sample of female youth participants supported this prediction (Kaufman and Flanagan 2015C). In this study, we compared two versions of the game that differed in their ratio of male-to-female scientists in the set of eight presented to players - one in which there were equal numbers of male and female scientists and one in which six of the eight scientists were female. Results revealed that, compared to participants in a no-game control condition, participants assigned to play the "intermixed" version of the game (but not those assigned to the "imbalanced" version) exhibited significantly higher levels of psychological connection to the game's luminists and, as a result, greater aspirations to pursue computer programming and other STEM careers and higher self-efficacy in STEM. 
Intermixing is counterintuitive. On the surface, the strategy may seem as though it would be less effective. Yet, despite the fact that players are exposed to less focal content (e.g., fewer scenarios depicting occurrences of bias in Awkward Moment or fewer female role models in The Luminists), they are significantly more likely to accept and internalize (rather than reject and defend against) the game's underlying persuasive aims and messages. Our work to date has shown that the "intermixing" strategy of balancing or interweaving on-topic, focal aspects of a game with off-message or off-topic content, plays a central role in determining the efficacy of our persuasive games.

\section{Embedding through "Obfuscating"}

The second broad embedding design strategy that we have employed with great success is "obfuscating": concealing or obscuring the true persuasive intent of a game by employing devices that divert players' attention and/or allow for the covert introduction of persuasive themes or elements. One primary example of the obfuscating method is the decision to employ a game genre whose associated goals or expectations do not include the aim to change players' attitudes, beliefs, or behaviors. Indeed, our choice to design the aforementioned Awkward Moment as a fast-paced, social party game was a wholly intentional one. Triggering (and fulfilling) the anticipation of a fun, interactive play experience with an abundance of levity and laughter (achieved in part through the game's "intermixing" of both serious and silly or absurd Moments and Reactions) created a "safe" space for players to encounter and react to the game's heavier, on-message content with greater comfort - and greater candor. Our team's extensive playtesting and iteration of the game provided consistent support; through both unobtrusive observations of play sessions and post-game interviews with youth testers, playgroups generally approached the game with a strong and sustained spirit of levity and amusement, yet rarely showed signs of subverting the game's more serious moments (or Moments), even among older, more experienced (or even more 'jaded') players at venues such as the PAX or GenCon gaming conventions. Moreover, even when asked directly what they believed the true goals of the game to be, players rarely identified the game's primary aim of challenging gender stereotypes in STEM domains, but rather focused more broadly on the game's general focus on reacting to a variety of social situations (further evidence of the successful implementation of the "intermixing" strategy) as well as a number of genreconsistent goals, such as the enjoyment of the game's social dynamics and the amusingly random or serendipitous pairings of Moment and Reaction cards that emerged.

In developing a second game with the same primary aim as Awkward Moment - to combat stereotypes and reduce prejudices - we went even a step further in using the party game genre to obfuscate the underlying goals. Buffalo: The Name Dropping Game (2012) is ostensibly a rapid-fire group trivia game: players flip a card from each of the game's two decks (one containing adjectives and the other nouns) and race to be the first to shout out the name of a real or fictional person who matches the revealed pair of descriptors (see Figure 3). What most players do not realize (and, as playtests and interviews have revealed, are quite surprised to learn) is that the game's deceptively simply design was based on an established psychological premise: exposure to a plethora of counterstereotypical or otherwise unexpected exemplars (to which players are necessarily exposed given the game's random pairings of attributes and social categories) reliably reduces individuals' levels of stereotyping and prejudice. In a given play session, for example, players may be invited to name such diverse exemplars as a "charismatic techie," "rugged fashion designer," "tattooed visionary," and "Iranian poet." Indeed, our own controlled experiments investigating the impact of Buffalo (Kaufman and Flanagan 2015A) revealed that players of a single session of the game, compared to participants in 
a no-game control condition, exhibited significantly higher levels of social identity complexity (i.e., greater diversity and inclusiveness in their perception of their primary identity groups, which is a predictor of tolerance and egalitarianism: Roccas and Brewer 2002) and universal orientation (i.e., a measure of global non-prejudice: Phillips and Ziller 1997). Thus, despite (or, we would argue, because of) players' general failure to realize or recognize the game's persuasive goals and mechanism, the game successfully shifts players' conceptions of their own and others' identities simply by virtue of playing the game and both offering and being exposed to a plethora of exemplars of cross-cutting identity groups and associated traits. Moreover, even in cases when players recognize how their own biases might have influenced their performance in the game (e.g., one playtest participant regretfully reflected on his and his group's failure to name a "Hispanic lawyer," despite the fact that Sonia Sotomayor had recently been appointed to the Supreme Court), they by and large do not realize that this was, in fact, a focal outcome intended by the game's designers.
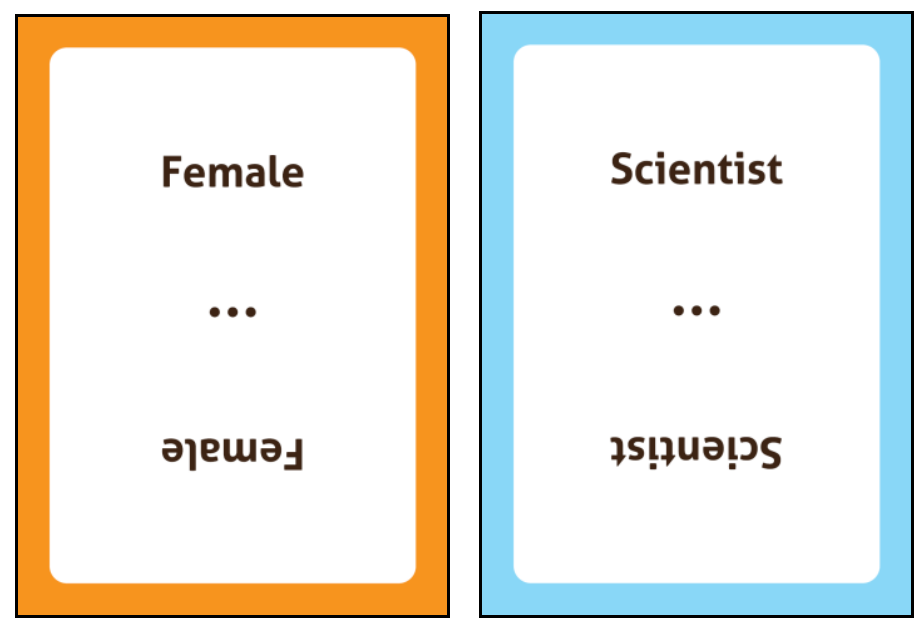

Figure 3: Sample card pairing from Buffalo: The Name Dropping Game.

With both Awkward Moment and Buffalo, we employed yet another means of obfuscation, one that is particularly rare among persuasive games: we deliberately avoided disclosing the aims of the game in the descriptions provided to players on the game box and in the instructional materials and instead used deliberately neutral language to present and explain the game. This choice of neutral language represents a second obfuscation strategy: the use of framing devices that emphasize features of the game other than its focal subject matter or persuasive aims. Indeed, we predicted that simply revealing before play that either game dealt in some way with social biases and stereotypes could dramatically reduce players' enjoyment of the game or the game's impact, in part because such "forewarning" would likely raise either conscious or unconscious defenses in players to resist the game's perceived intent. An initial pair of randomized experiments (Kaufman and Flanagan 2015A) suggested that this was indeed the case. Holding all other game elements constant, adolescent players of Awkward Moment who were randomly assigned to a "stereotype frame" condition (and were informed prior to play that the game dealt with "awkward social stereotypes"), compared to those assigned to a "situation frame" condition (who were told the game dealt with "awkward social situations") reported finding the game significantly less fun and immersive and failed to exhibited significantly less movement in their rejection of gender 
stereotypes. Likewise, playgroups who were told that Buffalo explored "pop culture stereotypes" (compared to "pop culture knowledge") did not show a reduction to their levels of prejudice, as assessed by the measure of universal orientation described above. These findings illustrate the basic premise of the "embedded design" model: persuasive games that overtly telegraph their intended purpose of shifting attitudes and mindsets are likely triggering mindsets in players that hinder the game's enjoyability and blunt its potential positive impact.

In addition to the selection of genres and the employment of framing language that diverts attention away from a game's true "message," one final obfuscation strategy that we have applied is the delayed revelation of potentially threatening, counter-attitudinal, or alienating features or elements. Specifically, we have explored this technique to encourage greater psychological connection and higher levels of experience-taking with characters (Kaufman and Libby 2012): that is, greater immersion into the role and persona of protagonists in narrative and game worlds, particularly ones who belong to social "outgroups." This technique has previously proven effective for written narratives: for example, revealing a character's racial or sexual orientation outgroup membership later in a short story (once a psychological connection between reader and character had begun to take root) not only facilitated higher levels of experience-taking but also reduced prejudice levels toward the represented outgroups (Kaufman and Libby 2012). That is, initially obfuscating the potentially distancing (or stigmatizing) group membership of the character ultimately increased readers' receptiveness of the character's identity - and profoundly enhanced the persuasive impact of the story.

More recently, our team successfully applied this technique to encourage higher levels of experience-taking among male youth in our strategy board game Monarch, which puts players in the role of sibling princesses competing for the throne. Given the persistence of social norms that discourage "gender-swapping" play, particularly among boys (e.g., Martin 1990; McCreary 1994), we anticipated that revealing their character's gender prior to play would reduce experience-taking among male adolescent players. Conversely, in line with prior research, withholding this revelation for several rounds (during which players became acquainted with their characters and were gradually exposed to subtle clues about their true identity, including the use of gowns and pageantry as political instruments in the game) should more effectively ease players into their cross-gender roles. This was indeed the case: a controlled experiment (Kaufman and Flanagan 2015D) revealed that a sample of male youth randomly assigned to play the "delayed revelation" version of the game, compared to those assigned to an "immediate revelation" version, reported higher levels of experience-taking with their princess characters and, moreover, exhibited greater rejection of stereotypical gender norms (e.g., rejection of the association between "female" and "emotional" or "weak") following gameplay.

\section{Embedding through "Distancing"}

The final embedded design strategy that we have explored in our work is the use of "psychological distance" (Trope and Liberman 2010) to create a safe space between individuals and the serious or sensitive themes or topics explored or modeled by a game. By separating players from their real-life identities and prior knowledge, beliefs, and experiences, persuasive games can effectively circumvent players' reticence or reluctance and enhance the game's transformative potential - particularly in subject matter domains that may be uncomfortable or counter-attitudinal. By its very nature, an absorbing, immersive game should trigger a high level of psychological transportation (Green and Brock 2000), thereby distancing players from their real-life surroundings and true 
identities, which prior work has shown sets the stage for higher levels of enjoyment (Green et al. 2004) and persuasion (Green and Brock 2000; Green, Brock, and Kaufman 2004; Kaufman and Libby 2012). Indeed, we would argue that persuasive games that take too overt or literal an approach in their handling of controversial or sensitive topics have inherently less capacity to transport their players (and to provide an enjoyable experience) because they create too little psychological distance to explore those topics in a non-threatening fashion.

Beyond the psychological distance afforded by a highly transporting game, however, there are a number of specific distancing strategies that designers can use to increase the gap between players' real-life experiences and the ideas, encounters, and interactions that await them in the game. These strategies are derived from a number of distinct manifestations of psychological distance revealed by prior work (Trope and Liberman 2000). Perhaps the most elementary forms of distance is hypotheticality: rather than presenting situations that are drawn directly from players' real-life experiences (or situations that attempt to replicate or mirror those experiences), encouraging players instead to engage in "what if?" scenarios provides a safe "buffer" to explore even the most sensitive topics. Indeed, the value of hypotheticality was a key decision point in the design of Awkward Moment: each of the game's Moment Cards present a purely hypothetical situation and invites players to consider a host of alternative ways of responding. Rather than placing the players and their embarrassing moments or experiences with bias in the spotlight, the game allows players to envision and select responses for the unidentified, second-person "you" described in each of the game's Moments.

A second distancing mechanism that we utilize in our work is the fictionalizing of reallife issues and events - that is, the embedding of those elements within symbolic, fantastical, or metaphorical representations. This technique is by no means a new one: the use of fiction to disguise the focus or target of a story may be as old as written language itself. What is distinctive in our approach to using fictional representations in games is our endeavor to systematically compare different levels of explicitness (versus "embeddedness") in those representations. To cite one example of this approach, our team has designed and studied two versions of the public health board game POX: Save the People (2011) intended to promote positive attitudes and valuations toward vaccination: one version $(P O X)$ that presented a relatively straightforward, realistic narrative about disease spread, and one version (ZOMBIEPOX) utilizing a more fantastical narrative about the spread of a "zombie plague" (see Figure 4). Both games share the same essential rules and mechanics concerning the spread of infectious disease and the modeling of vaccination as an effective strategy for curtailing that spread, but differ in the level of distance afforded by their representation of disease, infection, and death (or "un-death" in the case of ZOMBIEPOX). A pair of controlled experiments comparing the impact of both games on both adult and youth players revealed parity between the games (compared to a no-game control condition) in terms of their impact on players' valuation of vaccination as a public health solution. At the same time, however, players of the zombie-themed version of the game reported higher levels of psychological transportation and higher levels of empathic concern toward individuals with infectious diseases, as assessed by self-report measures (Kaufman, Flanagan, and Belman 2015). Thus, the use of a more distanced, metaphorical representation of disease was not only effective at shifting attitudes toward a real-life health policy issue but, indeed, even more effective than the less distanced, realistic narrative at forging a bond of compassion between players and the real-life individuals symbolized by the zombies in the game. 
This finding lends further credence to our view that persuasive games utilizing elements of the Embedded Design model (such as distancing) are likely to be experienced as more transporting by players - and, consequently, more impactful at changing hearts and minds.
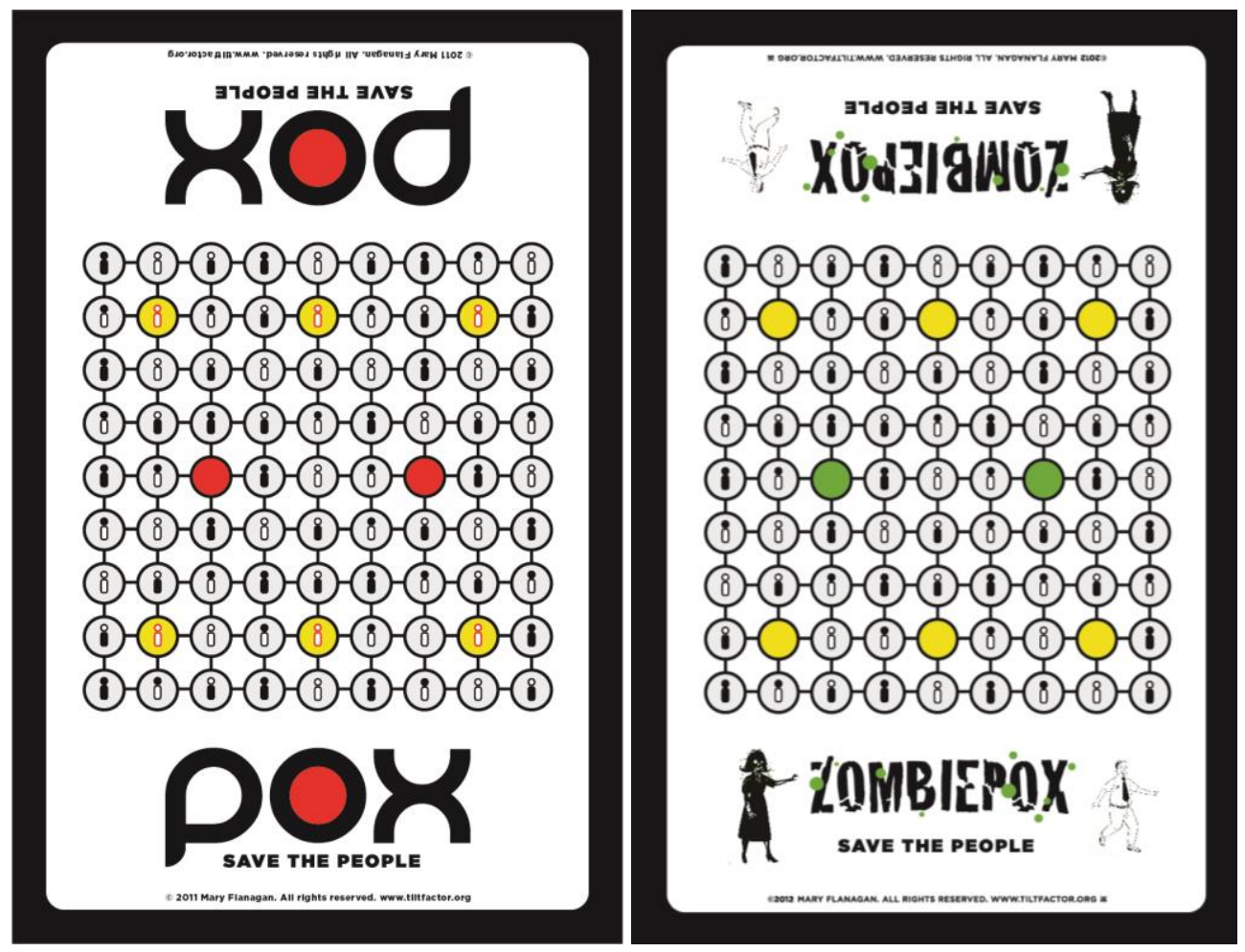

Figure 4: $P O X$ and $Z O M B I E P O X$ game boards.

In upcoming work, we will be exploring the benefits of fictionalized distancing for individuals creating narrativized accounts of their own real-life experiences - specifically, personal reflections on their experiences being the target of others' stereotypes and biased expectations, judgments, or behaviors. This project will explore the therapeutic and cathartic value of creating interactive "text adventures" that are based on stressful or traumatic real-life occurrences but provide creators with the safety (and creative license) afforded by the fictionalized re-telling and recounting of those life events. In this stream of research, we will investigate the effects of writing interactive narratives that are more fictionalized versus more strictly autobiographical, as well as the impact of a number of other distancing mechanisms, such as the narrative voice (e.g., a more distanced 3rd person voice versus the less distanced 1st and 2nd person perspectives) employed by authors, on the emotional benefits of narrativizing one's own lived experiences.

\section{CONCLUSION}

The Embedded Design model offers a number of easily implementable, evidence-based techniques that promise to revolutionize the ways that game developers tackle serious content issues and make more effective and more enjoyable games. As illustrated by examples from our own game designs and accompanying empirical work, the more covert, "stealthy" approaches derived from the Embedded Design model result persuasive games that are remarkably more transporting and impactful compared to games in which the message or material is presented more overtly or directly. Additionally, the model 
advances the conversation around the application of psychological principles in games and builds on other theoretical and practical formulations for understanding games, such as models of game design patterns (Bjork and Holopainen 2004).

The data emerging from empirical work on the use of embedding (via techniques such as intermixing, obfuscating, and distancing) demonstrates that such techniques invite a more open mindset, one characterized by a reduced level of activation and accessibility of players' self-concept and predispositions, attitudes, and beliefs. Such a mindset circumvents the psychological resistance that players are likely to experience to more overt, explicit game "interventions," and, further, sets the stage for players to approach and internalize new information and ideas, take on new perspectives and roles, and understand concepts or principles in a comparatively unbiased fashion. Indeed, the power of the embedded approach is that it offers design solutions that have the potential to be equally effective for both individuals who may already endorse a particular stance as well as those who may initially be opposed or indifferent to it. These strategies can enable games that address social issues to have a much broader impact.

It is important to note that the strategies described here are by no means intended to be comprehensive. Our team has just begun to discover the potential of such techniques. Each new game project we (and others) take on sets the stage for new manifestations and applications of embedding to emerge and, as a result, extend, enhance, and refine the design model introduced here. Moreover, although the game case studies we presented here to exemplify the model were non-digital, the principles and practices suggested by the model are intended to be broadly implemented across all game platforms and media delivery formats. Indeed, the greater flexibility and control afforded by the creation of digital games (e.g., in their revelation of information or representation of characters) open up a world of new possibilities for embedding that designers can consider, implement, and test in their own work (e.g., see Christiansen 2014).

\section{ACKNOWLEDGMENTS}

This research was supported by the U.S. National Science Foundation, HRD-1137483 "(EAGER) Transforming STEM For Women and Girls: Reworking Stereotypes \& Bias." Special thanks to the entire Tiltfactor team for their contributions and practical work, which helped inform the design model and applications offered here.

\section{BIBLIOGRAPHY}

Bjork, S., and Holopainen, J. Patterns in Game Design. Charles River Media, Newton Center, MA, 2004.

Bogost, I. Persuasive games: The expressive power of videogames. The MIT Press, Cambridge, MA, 2007.

Brehm, J.W. A Theory of Psychological Reactance. Academic Press, New York, 1966.

Centieiro, P., Romão, T., and Dias, A.E. "A location-based multiplayer mobile game to encourage pro-environmental behaviours," in Proceedings of the 8th International Conference on Advances in Computer Entertainment Technology (Lisbon, Portugal, November 2011), ACM Press, p. 31.

Christiansen, P. "Presence and heuristic cues: Cognitive approaches to persuasion in games," in Proceedings of DiGRA 2014 (Salt Lake City, UT, August 2014). 
Dasgupta, N., and Asgari, S. "Seeing is believing: Exposure to counterstereotypic women leaders and its effect on the malleability of automatic gender stereotyping," in Journal of Experimental Social Psychology vol. 40, no. 5 (2004), pp. 642-658.

de la Hera Conde-Pumpido, T. "A conceptual model for the study of persuasive games," in Proceedings of DiGRA 2013 (Atlanta, GA, August 2013).

Dunbar, N. E., Wilson, S. N., Adame, B. J., Elizondo, J., Jensen, M. L., Miller, C. H., ... and Burgoon, J. K. "MACBETH: Development of a training game for the mitigation of cognitive bias," in International Journal of Game-Based Learning (IJGBL), vol. 3, no. 4 (2013), pp. 7-26.

Flanagan, M. Critical Play: Radical Game Design. The MIT Press, Cambridge, MA, 2009.

Flanagan, M. and Nissenbaum, H. Values at Play in Digital Games. The MIT Press, Cambridge, MA, 2014.

Fiellin, L.E., Hieftje, K., Duncan, L.R., Sawyer, B.G., and Fiellin, D.A. “A videogame for substance use prevention and HIV risk reduction in young adolescents," in Drug and Alcohol Dependence, vol. 140 (2014), pp. e58-e59.

Green, M.C., and Brock, T.C. "The role of transportation in the persuasiveness of public narratives," in Journal of Personality and Social Psychology, vol. 79, no. 5 (2000), pp. 701-721.

Green, M.C., Brock, T.C., and Kaufman, G.F. "Understanding media enjoyment: The role of transportation into narrative worlds," in Communication Theory, vol. 14, no. 4 (2004), pp. 311-327.

Huizinga, J. Homo Ludens. Versuch einer Bestimmung des Spielelements in der Kultur. Rowohlt, Hamburg, 1938.

Kaufman, G., and Flanagan, M. "A Psychologically "Embedded" Approach to Designing Games for Prosocial Causes." Under Review (2015A).

Kaufman, G. and Flanagan, M. "How Awkward! Shifting Workplace Biases with a Social Game." Under Review (2015B).

Kaufman, G. and Flanagan, M. "How STEM Role Models Shift Thinking About STEM Careers in a Time Travel Game." Under Review (2015C).

Kaufman, G., and Flanagan, M. "Not Just for Girls: A Strategy Princess Board Game that Challenges Gender Stereotypes." Under Review (2015D).

Kaufman, G., Flanagan, M. and Belman, J. "Playing the System: Comparing the Efficacy and Impact of Digital and Non-digital Versions of a Collaborative Strategy Game," Under Review (2015).

Kaufman, G. F., and Libby, L. K. "Changing beliefs and behavior through experiencetaking," in Journal of Personality and Social Psychology, vol. 103, no. 1 (2012), pp. 1-16.

Martin, C. L. "Attitudes and expectations about children with nontraditional and traditional gender roles," in Sex Roles, vol. 22, no. 3-4 (1990), pp. 151-166.

McCreary, D.R. "The male role and avoiding femininity," in Sex Roles, vol. 31, no. 910 (1994), pp. 517-531.

Phillips, S. T., and Ziller, R. C. "Toward a theory and measure of the nature of nonprejudice," in Journal of Personality and Social Psychology, vol. 72, no. 2 (1997), pp. 420-434.

Pronin, E., Lin, D.Y., and Ross, L. "The bias blind spot: Perceptions of bias in self versus others," in Personality and Social Psychology Bulletin, vol. 28, no. 3 (2002), pp. 369-381.

Roccas, S., and Brewer, M.B. "Social identity complexity," in Personality and Social Psychology Review, vol. 6, no. 2 (2002), pp. 88-106. 
Trope, Y., and Liberman, N. "Construal-level theory of psychological distance," in Psychological Review, vol. 117, no. 2 (2010), pp. 440-463.

Worchel, S., and Brehm, J. W. "Effect of threats to attitudinal freedom as a function of agreement with the communicator," in Journal of Personality and Social Psychology, vol. 14, no. 1 (1970), pp. 18-22. 